\title{
Yolk-shelled $\mathrm{ZnCo}_{2} \mathrm{O}_{4}$ microspheres: Surface properties and gas sensing application
}

\author{
Nirav Joshi ${ }^{\mathrm{a}, \mathrm{b}, *}$, Luís F. da Silva ${ }^{\mathrm{c}}$, Harsharaj S. Jadhav ${ }^{\mathrm{d}}$, Flavio M. Shimizu ${ }^{\mathrm{a}}$, \\ Pedro H. Suman ${ }^{\mathrm{e}}$, Jean-Claude M'Peko ${ }^{\mathrm{a}}$, Marcelo Ornaghi Orlandi ${ }^{\mathrm{e}}$, Jeong Gil Seo ${ }^{\mathrm{d}}$, \\ Valmor R. Mastelaro ${ }^{\mathrm{a}}$, Osvaldo N. Oliveira Jr ${ }^{\mathrm{a}}$ \\ a São Carlos Institute of Physics, University of São Paulo, CP 369, São Carlos 13560-970, São Paulo, Brazil \\ ${ }^{\mathrm{b}}$ Department of Mechanical Engineering, University of California, Berkeley, USA \\ c Department of Physics, Federal University of São Carlos, Rodovia Washington Luis km 235, 13565-905 São Carlos, SP, Brazil \\ ${ }^{\mathrm{d}}$ Department of Energy Science and Technology, Myongji University, Cheoin-gu, Yongin-si, South Korea \\ e Department of Physical-Chemistry, Institute of Chemistry, São Paulo State University, P.O. Box 355, 14800-900 Araraquara, SP, Brazil
}

\section{A R T I C L E I N F O}

\section{Article history:}

Received 13 July 2017

Received in revised form 6 November 2017

Accepted 9 November 2017

Available online 11 November 2017

\section{Keywords:}

Zn-Co glycolate

$\mathrm{ZnCo}_{2} \mathrm{O}_{4}$

Co-precipitation

Yolk-shelled structures

Ozone gas sensing

Impedance spectroscopy

\begin{abstract}
A B S T R A C T
The need to improve the sensitivity, selectivity and stability of ozone gas sensors capable of monitoring the environment to prevent hazard to humans has sparked research on binary metal oxides. Here we report on a novel ozone gas sensor made with ca. $0.5 \mu \mathrm{m}$ yolk-shelled $\mathrm{ZnCo}_{2} \mathrm{O}_{4}$ microstructures synthesized via an eco-friendly, co-precipitation method and subsequent annealing. With these $\mathrm{ZnCo}_{2} \mathrm{O}_{4}$ microspheres, ozone concentrations down to 80 parts per billion (ppb) could be detected with a.c. and d.c. electrical measurements. The sensor worked within a wide range of ozone concentrations, from 80 to $890 \mathrm{ppb}$, being also selective to ozone compared to $\mathrm{CO}, \mathrm{NH}_{3}$ and $\mathrm{NO}_{2}$. The high performance could be attributed to the large surface area to volume ratio inherent in yolk-shell structures. Indeed, ozone molecules adsorbed on the $\mathrm{ZnCo}_{2} \mathrm{O}_{4}$ surface create a layer of holes that affect the conductivity, as in a p-type semiconductor. Since this mechanism of detection is generic, $\mathrm{ZnCo}_{2} \mathrm{O}_{4}$ microspheres can be further used in other environment monitoring devices.
\end{abstract}

(ㄷ) 2017 Elsevier B.V. All rights reserved.

\section{Introduction}

Monitoring toxic and harmful gases is now considered essential all over the world [1-5], owing to the increasing release of harmful gases, liquids and chemicals from industrial effluents, agricultural chemicals and fertilizers [6]. Toxic air pollutants such as $\mathrm{CO}$, $\mathrm{NO}_{2}$ and $\mathrm{NH}_{3}$ have been detected with chemiresistor gas sensors based on metal oxides $[7,8]$, which still require improvements to reach the selectivity needed for practical applications [9]. Ozone $\left(\mathrm{O}_{3}\right)$ is a potentially harmful gas that has received less attention, in spite of its effects on the human respiratory system that may cause loss of consciousness [6]. Continuous monitoring ozone in the environment is therefore important $[10,11]$, as exposure to ozone levels above $120 \mathrm{ppb}$ should be avoided, according to European Guidelines (2002/3/EG) [12,13]. Sensors made with metal semicon-

\footnotetext{
* Corresponding author at: São Carlos Institute of Physics, University of São Paulo, CP 369, São Carlos 13560-970, São Paulo, Brazil.

E-mail addresses: nirav.joshi1986@gmail.com, nirav.joshi@berkeley.edu (N. Joshi).
}

ducting oxides are normally uncapable to meet the requirement of detecting ozone at the ppb level [14]. There are exceptions though, including some n-type semiconductors, viz. $\mathrm{ZnO}$ [15], $\mathrm{SnO}_{2}$ [16], $\mathrm{WO}_{3}$ [17], $\alpha-\mathrm{AgWO}_{4}$ [18], $\mathrm{NiCo}_{2} \mathrm{O}_{4}$ [19] and $\mathrm{In}_{2} \mathrm{O}_{3}$ [20], especially the nanocrystalline $\mathrm{In}_{2} \mathrm{O}_{3}$ films able to operate at room temperature and detect ozone levels down to 15 ppb [21]. Despite the high sensitivity of the latter n-type semiconductor sensors, issues have to be addressed to improve stability and decrease response and recovery times [22]. Even more challenging is to achieve such high sensitivity if sensors based on p-type semiconductors are used [22].

Another possible avenue to enhance sensitivity and stability is to prepare gas sensors with binary metal oxides, which can be produced with a variety of methods, including hydrothermal [23-26], co-precipitation/digestion [27,28], microemulsion [29], template-assisted synthesis [30,31], pyrolysis [32,33], solvothermal [34-37] and thermal decomposition [38,39] methods. The resulting binary metal oxides $\left(\mathrm{AB}_{2} \mathrm{O}_{4}\right)$ may adopt shapes such as nano/microflowers, nanowires, nanoarrays, nanorods, and hollow microspheres [40]. Gas sensors with these binary oxides have been used for detection of carbon monoxide, Liquefied Petroleum Gas 
(LPG), chlorine, ethanol, formaldehyde $[27,29,30,33,41]$ in addition to ozone with p-type hexagonal platelets [19].

In this study, we build upon the successful use of binary metal oxides for sensing, now employing binary oxides made of cobalt and zinc. This choice was motivated by the high electronic conductivity and electrochemical activity of zinc cobalt oxide $\left(\mathrm{ZnCO}_{2} \mathrm{O}_{4}\right)$ used in Li-ion batteries [42] and as a hole transport layer in organic photovoltaics (PVs) [43]. Nanostructured $\mathrm{ZnCo}_{2} \mathrm{O}_{4}$ in distinct shapes has been used to detect volatile organic compounds (VOCs) [29,30], such as methanol, formaldehyde, acetone and ethanol $[22,34,44]$. Here, we report on the use of $\mathrm{ZnCo}_{2} \mathrm{O}_{4}$ yolkshell microspheres, synthesized in a cost-effective, eco-friendly co-precipitation method, for detecting ozone with electrical measurements. Significantly, a high sensitivity was reached with the high surface area to volume ratio inherent in yolk-shell structures.

\section{Experimental section}

The chemical reagents zinc (II) acetate $\left(\mathrm{Zn}\left(\mathrm{CH}_{3} \mathrm{COO}\right)_{2} \cdot 2 \mathrm{H}_{2} \mathrm{O}\right.$ (99\%)), cobalt (II) acetate $\left(\mathrm{Co}\left(\mathrm{CH}_{3} \mathrm{COO}\right)_{2} \cdot 4 \mathrm{H}_{2} \mathrm{O}(99 \%)\right)$, and ethylene glycol $\left(\mathrm{HOCH}_{2} \mathrm{CH}_{2} \mathrm{OH}\right.$, A.R.) were supplied by Sigma-Aldrich Co. LLC. and used without any further purification.

\subsection{Synthesis of $\mathrm{ZnCo}_{2} \mathrm{O}_{4}$ yolk-shell microspheres}

The $\mathrm{ZnCo}_{2} \mathrm{O}_{4}$ compound was synthesized using the coprecipitation method [45], in which $\mathrm{ZnCo}_{2} \mathrm{O}_{4}$ microspheres were prepared by dissolving $2 \mathrm{mM}$ of zinc acetate and $4 \mathrm{mM}$ of cobalt acetate in $50 \mathrm{~mL}$ ethylene glycol(EG), left under vigorous stirring for $30 \mathrm{~min}$. This homogeneous solution was then transferred to a glass container, which was kept in an oil bath for $2 \mathrm{~h}$ at $170^{\circ} \mathrm{C}$, followed by cooling down to room temperature. The precipitate powder was washed several times with deionized water, ethanol and acetone. This powder was then dried in a vacuum oven overnight at $80^{\circ} \mathrm{C}$, after which it was heated in an electric furnace to $350^{\circ} \mathrm{C}$ at a heating rate of $1{ }^{\circ} \mathrm{Cmin}^{-1}$ during $5 \mathrm{~h}$, leading to crystalline $\mathrm{ZnCo}_{2} \mathrm{O}_{4}$ powder. The synthesis procedure of pristine $\mathrm{ZnCo}_{2} \mathrm{O}_{4}$ is schematically illustrated in Fig. S1 in the electronic Supplementary information.

\subsection{Material characterization}

The crystalline phase of $\mathrm{ZnCo}_{2} \mathrm{O}_{4}$ samples was identified by $\mathrm{X}$-ray diffraction (XRD), using $\mathrm{CuK} \alpha$ radiation (Rigaku, Rotaflex $\mathrm{RU}-200 \mathrm{~B})$ in the $2 \theta$ range from $10^{\circ}$ to $80^{\circ}$ with a step of $0.02^{\circ}$ and step scanning of $2^{\circ} \mathrm{min}^{-1}$. The morphological characteristics of $\mathrm{ZnCo}_{2} \mathrm{O}_{4}$ microspheres were analyzed by field emission scanning electron microscopy (FE-SEM, Zeiss Sigma) operating at $5 \mathrm{kV}$, equipped with X-ray energy dispersive spectroscopy (EDS). Sample cross-sections were obtained in a dual-beam microscope (FEI Helios NanoLab 600i). The phase and crystallinity of $\mathrm{ZnCo}_{2} \mathrm{O}_{4}$ were further investigated using transmission electron microscopy (TEM; Philips, CM200) operated at $200 \mathrm{kV}$. Thermo-gravimetric analysis (TGA) was carried out using a thermogravimetric analyzer (Perkin Elmer TGA7) at a scan rate of $10^{\circ} \mathrm{C} \mathrm{min}^{-1}$ in air. The specific surface area and pore size distribution of the material were estimated using the Brunauer-Emmett-Teller (BET) method based on the nitrogen adsorption-desorption isotherms (BELSORP-mini II, Japan). The composition and chemical state of the final products were analyzed by X-ray photoelectron spectroscopy (XPS) using an ESCALAB-MKII spectrometer (UK) with $\mathrm{Al} \mathrm{K \alpha}$ radiation $(1486.6 \mathrm{eV}$ ) as the X-ray source for excitation. The binding energies (BEs) were evaluated using $\mathrm{C} 1 \mathrm{~s}$ spectrum $(\mathrm{BE}=284.6 \mathrm{eV})$ as the reference with an accuracy of $\pm 0.1 \mathrm{eV}$.

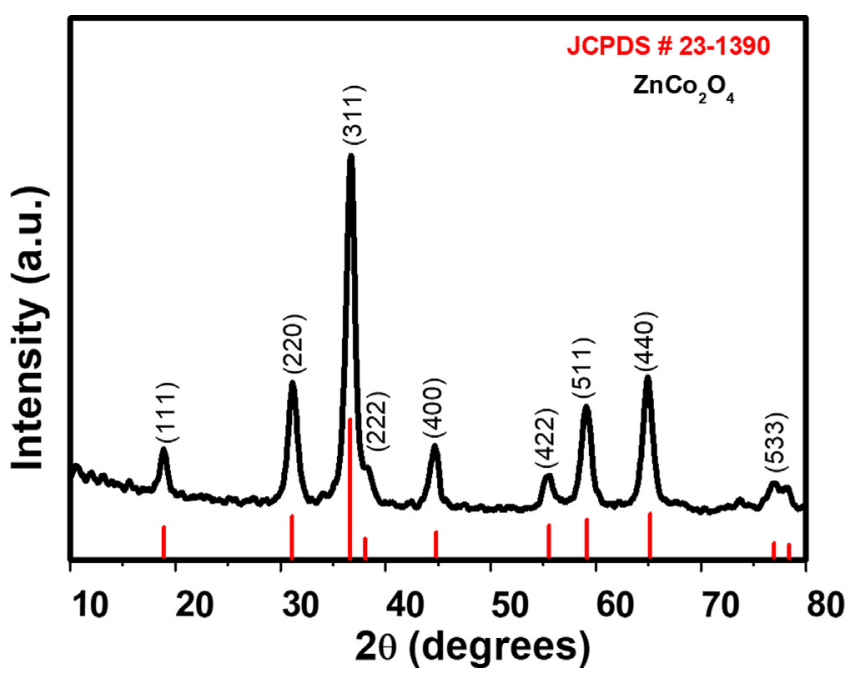

Fig. 1. XRD pattern of $\mathrm{ZnCo}_{2} \mathrm{O}_{4}$ annealed at $350{ }^{\circ} \mathrm{C}$ for $5 \mathrm{~h}$ in ambient atmosphere.

\subsection{Fabrication of $\mathrm{ZnCo}_{2} \mathrm{O}_{4}$ sensing film and gas-sensing measurements}

Gas sensing devices were fabricated by ultrasonically dispersing the as-prepared $\mathrm{ZnCo}_{2} \mathrm{O}_{4}$ powders $(10 \mathrm{mg})$ in $1 \mathrm{~mL}$ isopropyl alcohol and the suspension was then drop-cast onto a $\mathrm{SiO}_{2} / \mathrm{Si}$ substrate containing $100 \mathrm{~nm}$ thick Pt electrodes separated by a distance of $50 \mu \mathrm{m}$. Details of preparation of the interdigitated electrodes (IDEs) are given in [19]. After dropping the $\mathrm{ZnCo}_{2} \mathrm{O}_{4}$ solution, the substrates were heated to $100^{\circ} \mathrm{C}$ for $10 \mathrm{~min}$ to evaporate the solvent, followed by calcination at $350^{\circ} \mathrm{C}$ for $2 \mathrm{~h}$ in an electric furnace in air to stabilize the sample before the gas sensing measurements. Pictures of the system to measure the chemiresistive gas sensing performance are shown in Fig. S2. The sensor was inserted into a chamber with temperature control from 100 to $300^{\circ} \mathrm{C}$ under different ozone concentrations. Dry air was used as both the reference and the carrier gas for all measurements, with a constant total flow of 500 SCCM kept via mass flow controllers. Ozone gas was formed by oxidation of oxygen molecules of dry air with a pen-ray UV lamp (UVP, model P/N 90-0004-01), which was calibrated using a toxic gas detector (ATI, model F12) that provided ozone level concentration in the range of $80-890 \mathrm{ppb}$. The applied $D C$ voltage was $1 \mathrm{~V}$ and the electrical resistance was measured using an electrometer Keithley (model 6514). The ozone-containing dry air was blown directly onto the sample, which was placed in a heated holder system. For gas sensing characterization, the sensors were exposed to $1 \mathrm{ppm}$ (parts-per-million) of various gases, namely nitrogen dioxide $\left(\mathrm{NO}_{2}\right)$, carbon monoxide $(\mathrm{CO})$ and ammonia $\left(\mathrm{NH}_{3}\right)$ controlled by mass flowmeters. Details of the gas-sensing experiments are available in [46]. The sensor response was calculated from the response curves using Eq. (1):

Sensor Response $(\%)=\left|\frac{\Delta R}{R_{a}}\right| \times 100$

where $\Delta R=R_{a}-R_{g}$ for oxidizing gases like ozone, and $R_{g}$ and $R_{a}$ are the electrical resistances of the sensor film with target gases and dry air, respectively. The response and recovery times were defined as the time needed for reaching $90 \%$ of total change in resistance upon exposure to the target gas and fresh air, respectively. During the measurements, the relative humidity was kept within the range $30-50 \% \mathrm{RH}$ (Termo-Higrometro model HT-700). The AC Impedance spectroscopy data were obtained with the $\mathrm{ZnCo}_{2} \mathrm{O}_{4}$ film using an impedance/gain-phase analyzer (Solartron SI 1260) in the frequency range from $1 \mathrm{~Hz}$ to $1 \mathrm{MHz}$ at an operating temperature of $200^{\circ} \mathrm{C}$. 

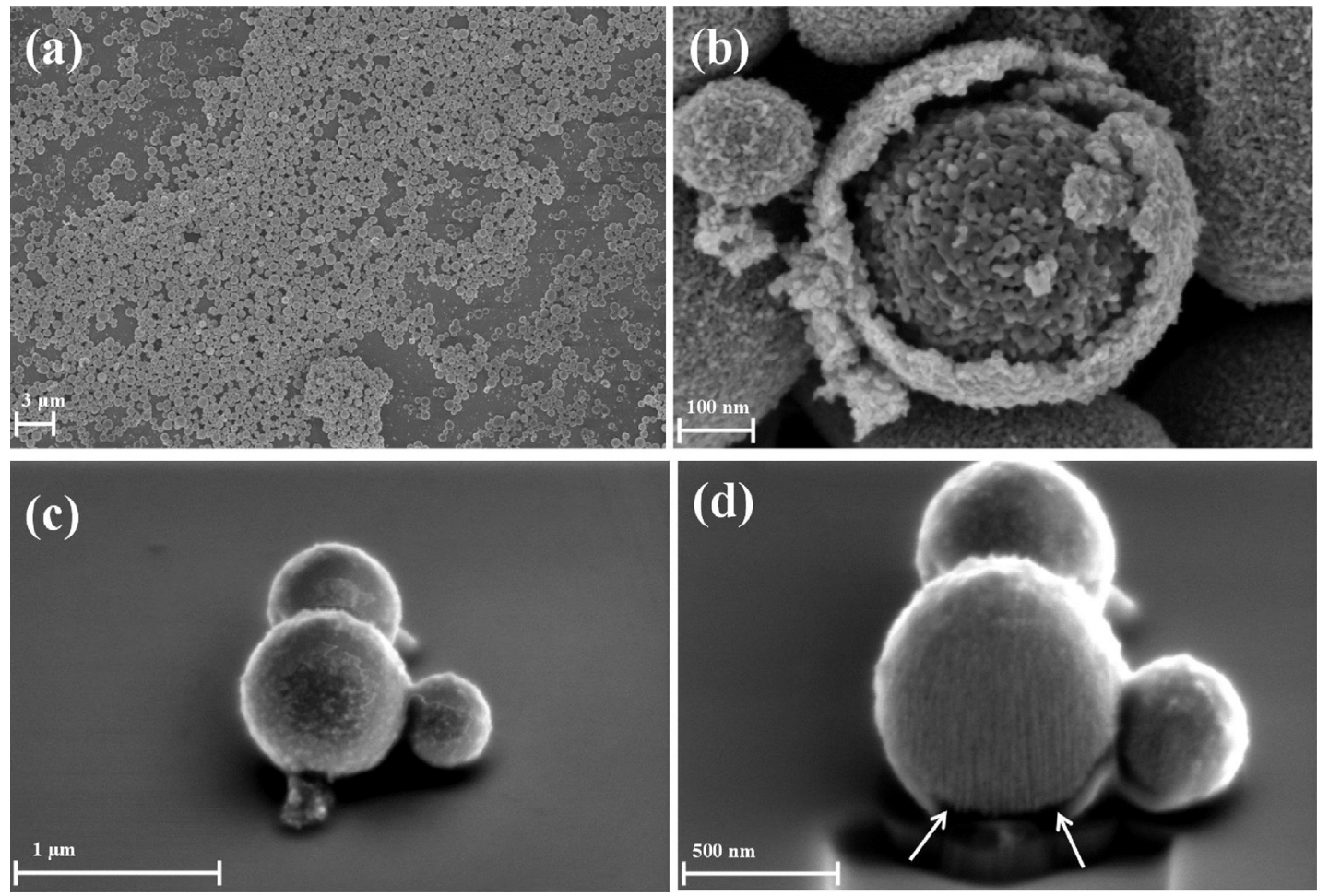

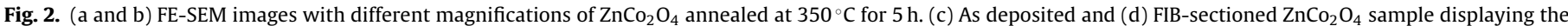
yolk and the shell parts.

\section{Results and discussion}

\subsection{Structural and microstructural characterizations}

$\mathrm{ZnCo}_{2} \mathrm{O}_{4}$ yolk-shelled microspheres were synthesized via an eco-friendly precipitation route without any surfactant. Fig. S3 shows the thermogravimetric analysis (TGA) curve of $\mathrm{ZnCo}-$ glycolate precursor which indicates a total weight loss of $45.5 \%$ above $300^{\circ} \mathrm{C}$. Two major weight loss steps were identified: the first loss of $\sim 12 \%$ up to $210^{\circ} \mathrm{C}$ is attributed to the release of chemically and physically adsorbed ethylene glycol and other organic molecules, while the other major weight loss of $33.5 \%$ is attributed to thermal decomposition of $\mathrm{ZnCo}$-glycolate into $\mathrm{ZnCo}_{2} \mathrm{O}_{4}$. Above $300^{\circ} \mathrm{C}$ no weight loss was observed, which confirms the formation of pure $\mathrm{ZnCo}_{2} \mathrm{O}_{4}$ phase. To ensure complete decomposition of the precursor, we chose $350^{\circ} \mathrm{C}$ as the calcination temperature for the synthesis of $\mathrm{ZnCO}_{2} \mathrm{O}_{4}$.

Fig. 1 displays the XRD pattern of $\mathrm{ZnCO}_{2} \mathrm{O}_{4}$ powder annealed for $5 \mathrm{~h}$ at $350^{\circ} \mathrm{C}$, where all reflections were indexed to a face-centeredcubic (fcc) arrangement with Fd3m (227) space group (JCPDS file No. 23-1390) and spinel structure, by comparing with the standard pattern illustrated by the vertical red lines.

The hysteresis on the $\mathrm{N}_{2}$ adsorption-desorption isotherms for the yolk-shelled $\mathrm{ZnCo}_{2} \mathrm{O}_{4}$ in Fig. S4 is classified as type III, with a type $\mathrm{H}_{4}$ hysteresis loop, according to IUPAC (International Union of Pure and Applied Chemistry). These are typical of mesoporous materials formed by agglomerated particles [47]. The BET specific surface area was $52.73 \mathrm{~m}^{2} \mathrm{~g}^{-1}$, with a pore volume of $0.10 \mathrm{~m}^{3} \mathrm{~g}^{-1}$. The pore size distribution, derived from desorption data and estimated from the isotherm using the Barrett-Joyner-Halenda (BJH) model (inset in Fig. S4), indicates a pore diameter ranging from 5 to $91 \mathrm{~nm}$, with an average of $10 \mathrm{~nm}$. This mesoporous structure is beneficial to sensing because the target gas molecule easily penetrates into the pores, thus leading to a larger analyte/sample contact area and providing interconnected paths that facilitate electron transport and accelerate species diffusion $[48,49]$.

Fig. 2(a) shows the spherical-like morphological features of $\mathrm{ZnCo}_{2} \mathrm{O}_{4}$ in the FE-SEM images, which are preserved upon calcination. A typical broken yolk-shelled microsphere is shown in Fig. 2(b). The core of the material is highly porous and composed of polycrystalline nanosized particles, in good agreement with BET results. The formation process of yolk-shelled microspheres is due to Ostwald ripening by minimization of surface energy [45]. In the synthesis, ZnCo-glycolate is formed due to interlinking of ethylene glycol at $170^{\circ} \mathrm{C}$; owing to a high surface energy and aggregation it turns into spheres with reduced free energy $[45,50]$. The yolkshelled structure arises from the heat treatment during thermal decomposition of ZnCo-glycolate under non-equilibrium conditions. As the temperature reaches $350^{\circ} \mathrm{C}$ during calcination, the $\mathrm{ZnCo}$-glycolate core starts to decompose into $\mathrm{ZnCo}_{2} \mathrm{O}_{4}$, thus eventually leading to a $\mathrm{ZnCo}_{2} \mathrm{O}_{4}$ yolk-shelled microsphere [45]. Fig. 2(c) illustrates the typical yolk-shell spheres while Fig. 2(d) shows the cross-section of the larger sphere made by FIB (Focused Ion Beam), confirming the small yolk surrounded by a thin shell (white arrows in Fig. 2(d)). The purity of the as-obtained $\mathrm{ZnCo}_{2} \mathrm{O}_{4}$ particles is ensured by the EDS mapping images in Fig. S5, where there are only $\mathrm{Zn}$, Co and $\mathrm{O}$ elements uniformly distributed throughout the structure, in addition to Si from the substrate.

The gap between the outer shell and the inner yolk in the microspheres is illustrated in the low and high magnification TEM images in Fig. 3(a) and (b). Some broken spheres do not possess a shell due to the ultrasound bath used for TEM sample preparation, as observed in Fig. 3(a). Details of a yolk-shell sphere are marked with a white box in Fig. 3(b), featuring a yolk diameter of $0.5 \mu \mathrm{m}$ and wall thickness of ca. $50 \mathrm{~nm}$. The selected area electron diffraction (SAED) pattern for spheres annealed at $350^{\circ} \mathrm{C}$ in Fig. 3(c) displays concentric rings, characteristic of polycrystalline materials. The diffraction rings are assigned as (111), (220), (311), (400), (422), (511) and (440) planes of the cubic structure of the $\mathrm{ZnCo}_{2} \mathrm{O}_{4}$ phase, consis- 

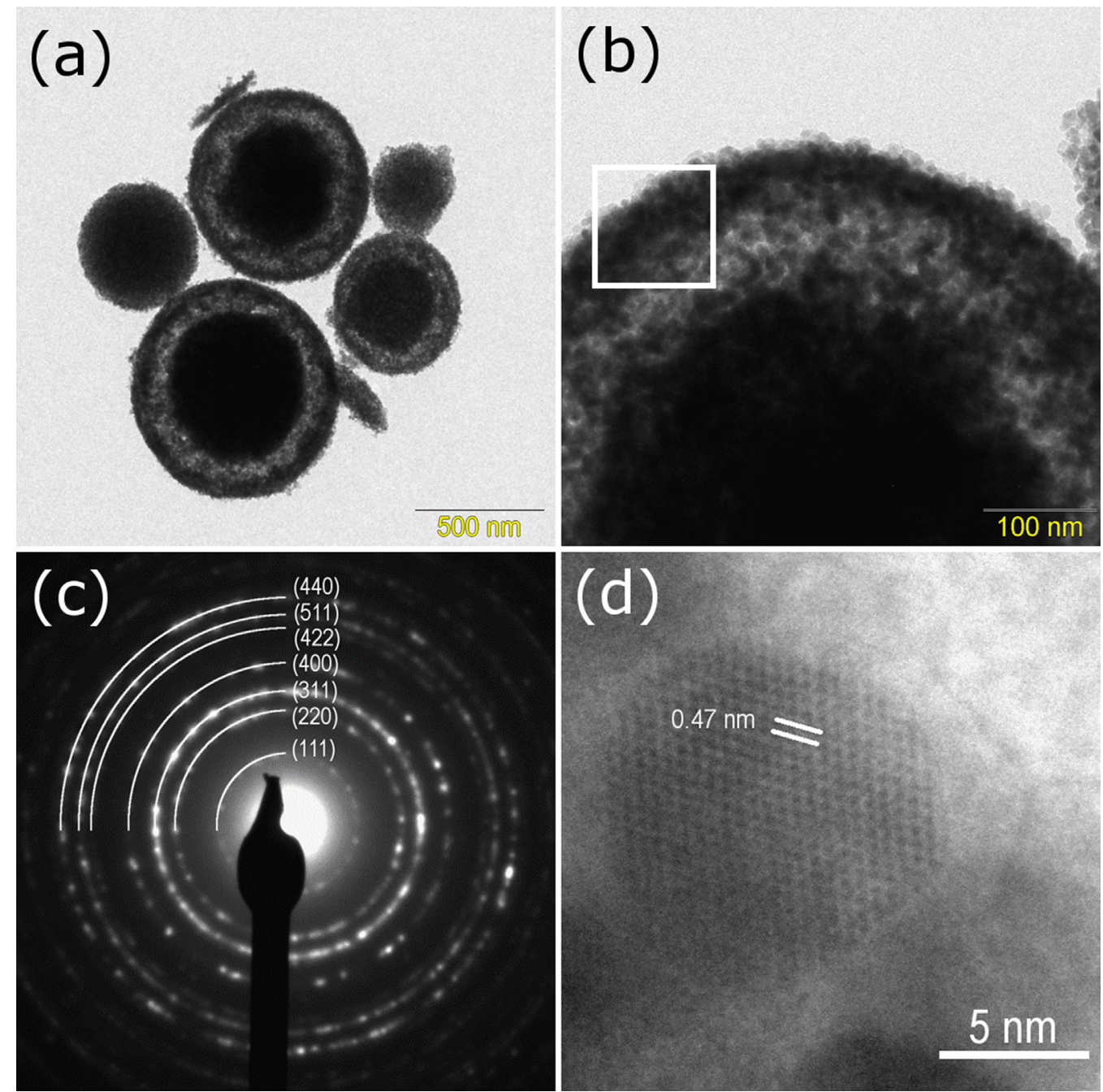

Fig. 3. ( $\mathrm{a}$ and b) Low and high magnification TEM images of the yolk-shelled $\mathrm{ZnCo}_{2} \mathrm{O}_{4}$ microspheres. (c) SAED pattern (d) HRTEM image at the edge of a microsphere.

tent with the XRD analysis. Fig. 3(d) shows the high resolution TEM image of a particle at the shell edge (white square region), where the interplanar distance is $0.47 \mathrm{~nm}$, corresponding to the (111) Miller indices of spinel-type $\mathrm{ZnCo}_{2} \mathrm{O}_{4}$ phase.

The chemical elements comprising the $\mathrm{ZnCo}_{2} \mathrm{O}_{4}$ yolk-shelled microspheres are inferred from the XPS spectra in Fig. 4. The survey XPS spectrum in Fig. 4(a) reveals the presence of C, Zn, Co, and O elements, with the absence of impurities. The appearance of the $\mathrm{C}$ peak is derived from adventitious carbon species. The high resolution XPS spectra of Zn 2p, Co 2p, and O 1s after Gaussian fitting are shown in Fig. 4(b-d). Two main peaks appear at 1020.8 and $1043.9 \mathrm{eV}$ for $\mathrm{Zn} 2 \mathrm{p}$ in Fig. 4(b), typical of $\mathrm{Zn}^{2+}$ with the orbits of $\mathrm{Zn} 2 \mathrm{p}_{3 / 2}$ and $\mathrm{Zn} 2 \mathrm{p}_{1 / 2}$, respectively [51]. The well resolved Co $2 \mathrm{p}$ spectrum in Fig. 4(c) shows peaks at 779.4 and $794.2 \mathrm{eV}$ assigned to Co $2 \mathrm{p}_{3 / 2}$ and Co $2 \mathrm{p}_{1 / 2}$, respectively, with spin-orbit splitting of around $15 \mathrm{eV}$ owing to mixed $\mathrm{Co}^{2+}$ and $\mathrm{Co}^{3+}$ ions [52-54]. The $\mathrm{O} 1 \mathrm{~s}$ XPS spectrum in Fig. 4(d) can be deconvoluted into three peaks. The lower energy peak at $529.2 \mathrm{eV}$ can be attributed to metal-oxygen bonding (oxygen bonding with $\mathrm{Zn}$ and $\mathrm{Co}$ ) in $\mathrm{ZnCo}_{2} \mathrm{O}_{4}$ [54,55]. The second peak at $530.9 \mathrm{eV}$ is assigned to oxygen of surface hydroxyl groups [56-58], while the third peak at $532.3 \mathrm{eV}$ is due to oxygen molecules chemisorbed onto the semiconductor surface [59].

\subsection{Gas sensing properties}

The gas sensing properties of $\mathrm{ZnCo}_{2} \mathrm{O}_{4}$ yolk-shelled microspheres were investigated by measuring the response of a sensor exposed to $560 \mathrm{ppb}$ of ozone at an operating temperature of $200^{\circ} \mathrm{C}$, with different exposure times $(15,30$, and $60 \mathrm{~s})$. Fig. 5(a) reveals that $\mathrm{ZnCo}_{2} \mathrm{O}_{4}$ microspheres were sensitive to ozone even for the shortest exposure time ( $15 \mathrm{~s}$ ), with no evidence of saturation upon increasing the time. Fig. S6 in the Supplementary material indicates that even after 3 min of exposure to ozone gas, the sample response was not fully saturated and the recovery time became longer than $30 \mathrm{~min}$. The lack of saturation is probably due to the high surface area to volume ratio of the microspheres [60-62] in addition to the insufficient time for the adsorption process to reach equilibrium. The optimum operating temperature was $200^{\circ} \mathrm{C}$, according to Fig. 5(b), similarly to traditional oxide gas sensors [15,63-65]. The reason why a peak in performance appears is as follows: the reaction kinetics of gases with oxygen species chemisorbed on an oxide surface becomes faster with increasing temperatures, but above $200^{\circ} \mathrm{C}$ the rate of desorption is higher than for adsorption, thus decreasing the response. Therefore, there is an optimum operating temperature, where adsorption and desorption processes reach equilibrium. We do not expect any structural change during the sensing measurements because the material had been annealed at a higher temperature than the sensing operating temperature 

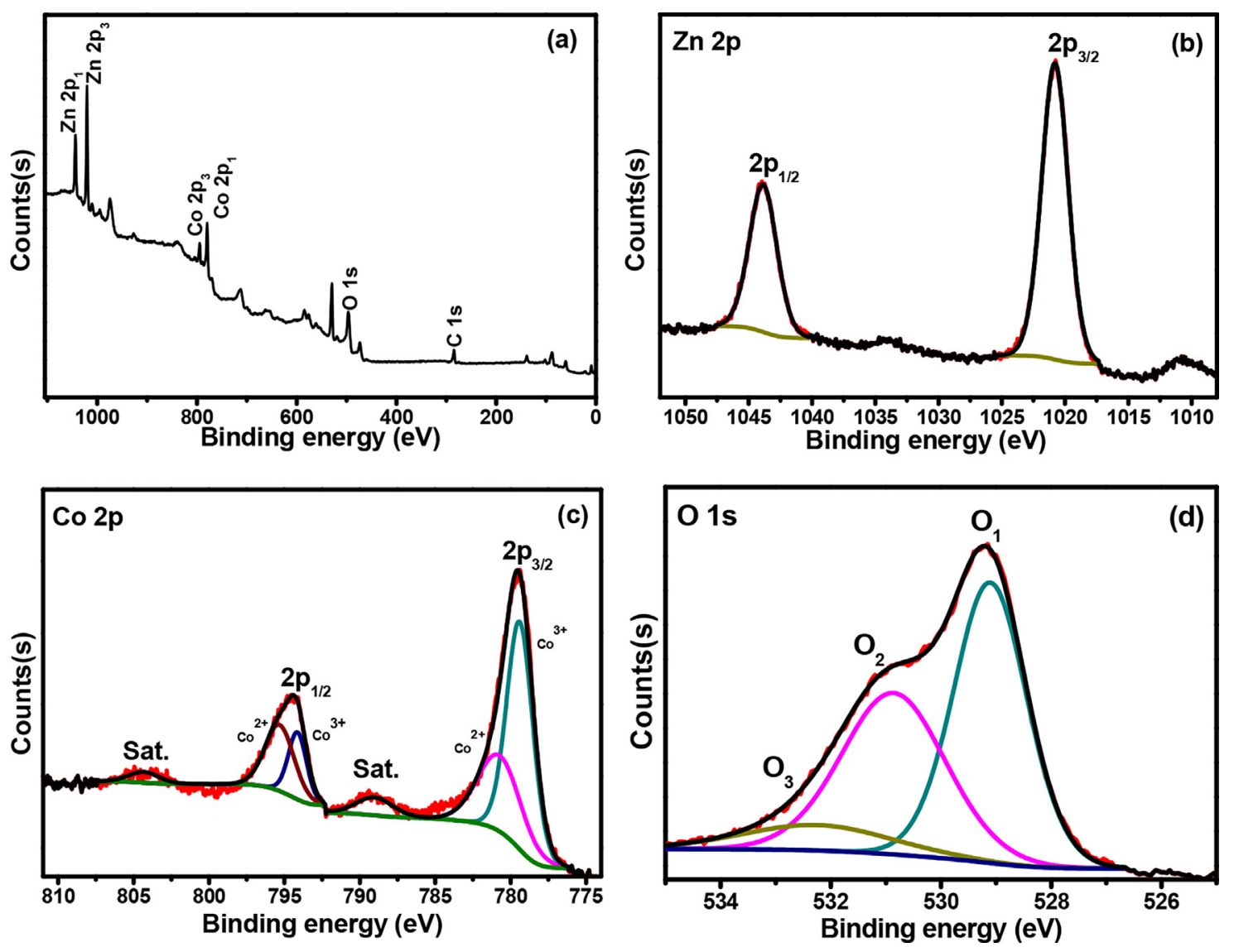

Fig. 4. XPS spectra of the $\mathrm{ZnCo}_{2} \mathrm{O}_{4}$ structure. (a) Survey scan and high resolution scan of (b) $\mathrm{Zn} 2 \mathrm{p}$, (c) Co 2p, and (d) O $1 \mathrm{~s}$ regions.

Table 1

Ozone gas sensing parameters for $\mathrm{ZnCo}_{2} \mathrm{O}_{4}$ microspheres at $200{ }^{\circ} \mathrm{C}$.

\begin{tabular}{llll}
\hline $\mathrm{O}_{3}$ level (ppb) & Sensor response (\%) & Response time (s) & Recovery time (min) \\
\hline 80 & 23.3 & 8.4 & 9.7 \\
290 & 35.5 & 12 & 17 \\
560 & 55 & 21 & 18 \\
890 & 71 & 37.4 & 21 \\
\hline
\end{tabular}

[55,66]. In subsidiary experiments we found that $\mathrm{ZnCo}_{2} \mathrm{O}_{4}$ yolkshelled microspheres could detect ozone even at lower operating temperatures, but the recovery time was too long or the original resistance could not be reached back. With regard to the concentration dependence, the response time varied from $8.4 \mathrm{~s}(80 \mathrm{ppb})$ to $37 \mathrm{~s}(890 \mathrm{ppb})$, while the recovery time varied from $9.7 \mathrm{~min}(80 \mathrm{ppb})$ to $21 \mathrm{~min}(890 \mathrm{ppb})$ as shown in Fig. 5(c).

It is worth noting that an ozone level above $120 \mathrm{ppb}$ is dangerous to human health, possibly causing problems such as lung damage. The $\mathrm{ZnCo}_{2} \mathrm{O}_{4}$ sensor displays total reversibility and good reproducibility in Fig. 6(a) when exposed to various ozone levels in three measurement cycles. The sample resistance decreased upon exposure to the oxidizing gas, which is indicative of p-type semiconductor behavior. The sensor response increases with ozone concentration and may even not reach saturation for $890 \mathrm{ppb}$, as indicated in Fig. 6(b). Due to the limitations of our gas sensing system, $80 \mathrm{ppb}$ is the lowest concentration that can be reliably delivered to the sensor device. Table 1 shows the sensing parameters with respect to different ozone levels.

Fig. 7 shows the sensor response of $\mathrm{ZnCo}_{2} \mathrm{O}_{4}$ yolk-shell microspheres exposed to $1 \mathrm{ppm}$ of reducing $\left(\mathrm{CO}\right.$ and $\left.\mathrm{NH}_{3}\right)$ and oxidizing $\left(\mathrm{O}_{3}\right.$ and $\left.\mathrm{NO}_{2}\right)$ gases at an operating temperature of $200^{\circ} \mathrm{C}$. One should note that for reducing gases the change in electrical resis- tance in Eq. (1) is given as $\Delta R=R_{g}-R_{a}$. The magnitude of the electrical resistance change was considerably higher for $\mathrm{O}_{3}(\sim 71 \%)$ than for $\mathrm{NO}_{2}(6.5 \%), \mathrm{NH}_{3}(3.8 \%)$ and $\mathrm{CO}(4.8 \%)$. Therefore, the $\mathrm{ZnCo}_{2} \mathrm{O}_{4}$ yolk-shell microspheres are very selective for ozone, which is promising for sensor devices. The response of this sensor film is also very stable, as indicated by the long-term stability measurements for over 30 days in Fig. S7 (a) and (b) in the electronic Supplementary information.

\subsection{Impedance spectroscopy measurements of $\mathrm{ZnCo}_{2} \mathrm{O}_{4}$ yolk-shell microspheres}

The $\mathrm{ZnCo}_{2} \mathrm{O}_{4}$ sensors were also tested for ozone detection through electrical impedance experiments, in concentrations ranging from $80 \mathrm{ppb}$ to $890 \mathrm{ppb}$ at a fixed operating temperature of $200^{\circ} \mathrm{C}$. Fig. 8(a) shows that the impedance data consists of a single semicircle in the Nyquist plot, whose diameter decreases with ozone concentration, consistent with the decreasing resistance upon ozone exposure discussed in the last subsection. In order to obtain further information about the contribution from each region of the sensor, the impedance data were successfully fitted with the equivalent electrical circuit shown in Fig. 9, which also depicts a schematic representation of the sensing sample under ozone flow. Table 2 brings the parameters extracted from data fitting. $R_{b}$ refers to the bulk contribution, which manifested here as a non-zero intercept of the impedance data with the real axis towards the highest frequencies; in passing, this parameter did not change under ozone flow. A similar behavior was found for the capacitance $C_{s}$, whose average value was $0.912 \times 10-{ }^{10} \mathrm{~F}$, close to the $\mathrm{nF}$ order often observed for surface effects $[67,68]$. We recall that the system under study contains a yolk-shell-modified particle-to-particle contact surface, the consequence of which is the observation of a 

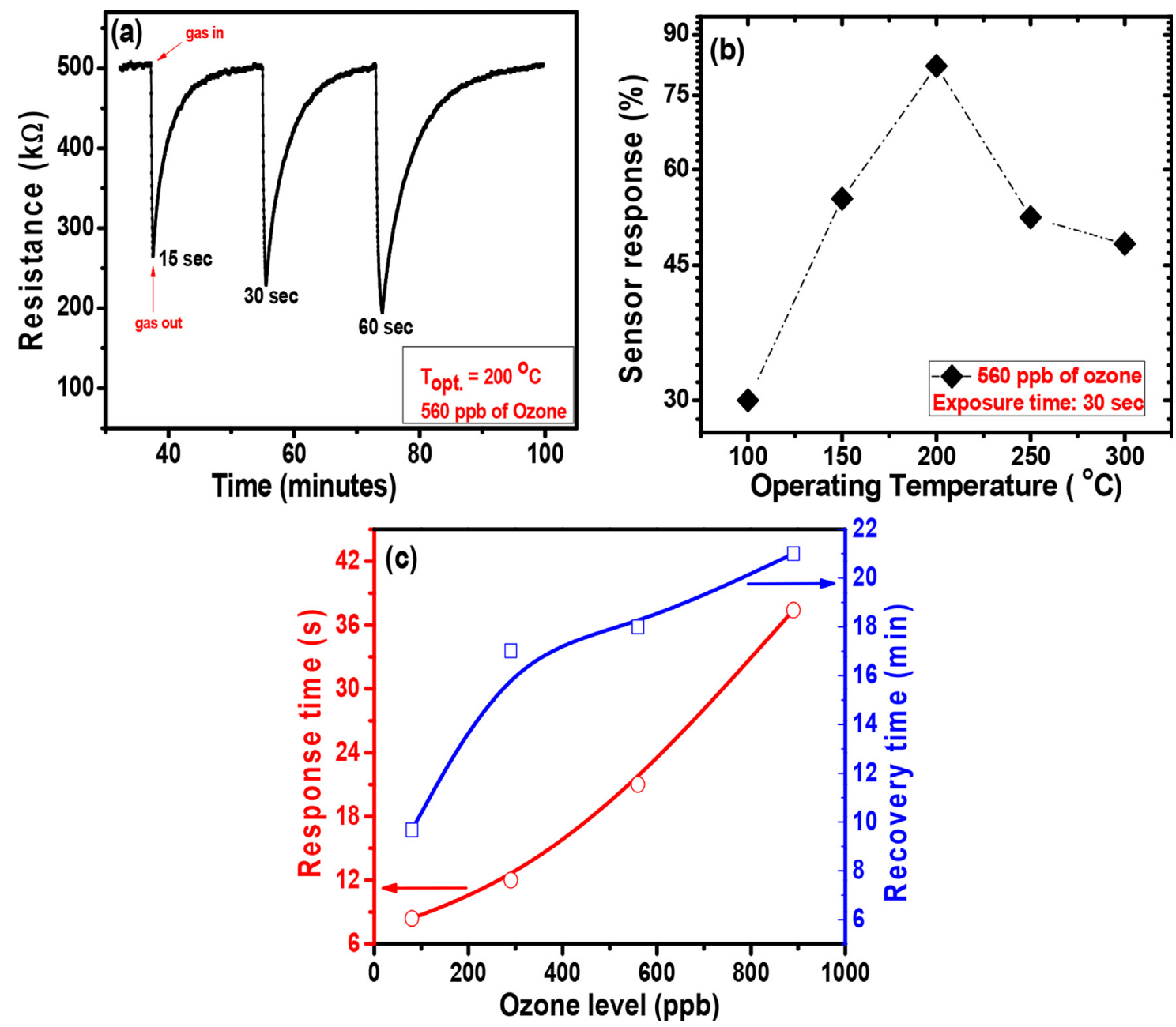

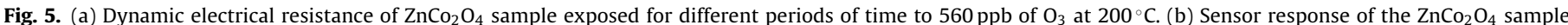
exposed to $560 \mathrm{ppb} \mathrm{O}_{3}$ at different operating temperatures. (c) Response and recovery time as a function of ozone concentration from 80 to $890 \mathrm{ppb}$ at $200{ }^{\circ} \mathrm{C}$.
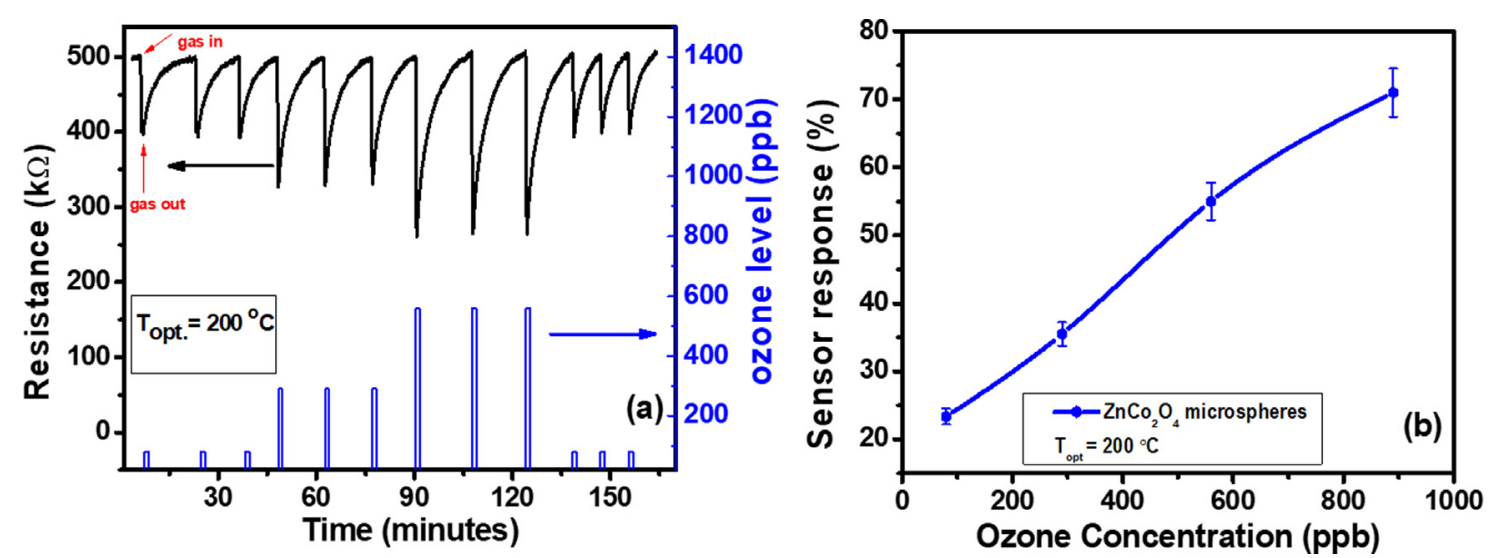

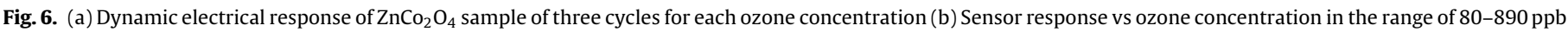
for $\mathrm{ZnCo}_{2} \mathrm{O}_{4}$ microspheres at $200^{\circ} \mathrm{C}$.

capacitance value somewhat lower than expected in typical surface effects. The resistance attributed to this surface-like contribution $\left(R_{S}\right)$, whose values are shown in Fig. 8(b), decreased with ozone concentration according to an exponential behavior. Note from Table 2 that $R_{S} \gg R_{b}$, meaning that these contact surfaces act as semi-blocking resistive regions. This is a charge storage effect (i.e., interface polarization of Maxwell-Wagner type [67]), giving rise to the capacitance component observed (impedance semicircle inci- dence) in Fig. 8(a). The change in impedance calculated from the Nyquist plot by subtracting the spectra before and after ozone exposure is depicted in Fig. 8(c). At high frequencies, the impedance did not vary with ozone concentration, but it did so between $1 \mathrm{~Hz}$ and $10 \mathrm{kHz}$ as the electrical response was dominated by surface contributions [69]. It is clear that ozone concentrations well below $80 \mathrm{ppb}$ could be detected, but this was not pursued owing to limitations of the sensor setup. The ozone sensing activity in this material, just 


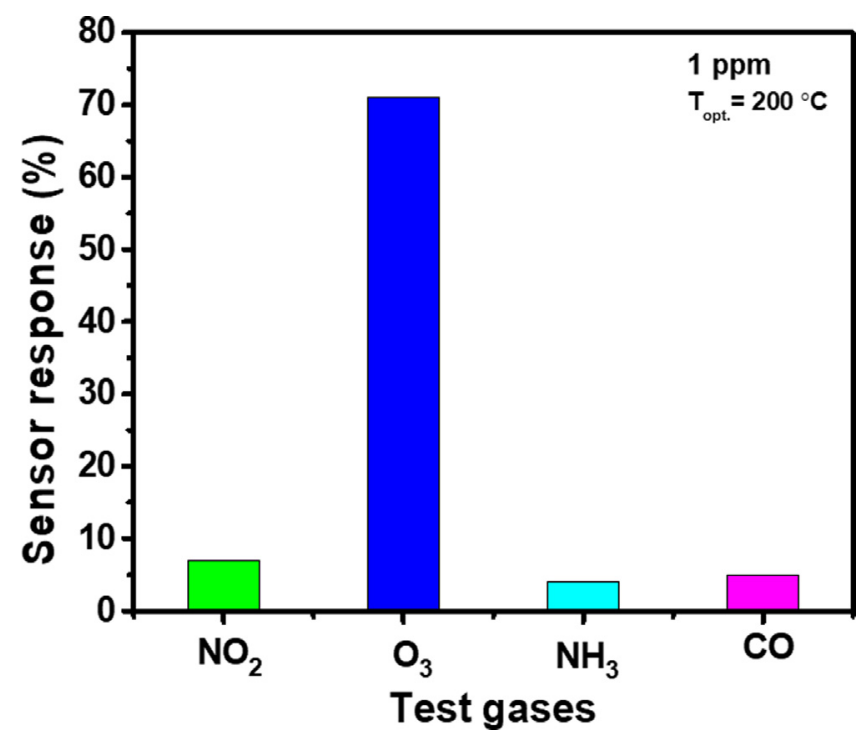

Fig. 7. Selectivity histogram of the $\mathrm{ZnCo}_{2} \mathrm{O}_{4}$ yolk-shell microspheres exposed to common gases present in the atmosphere.
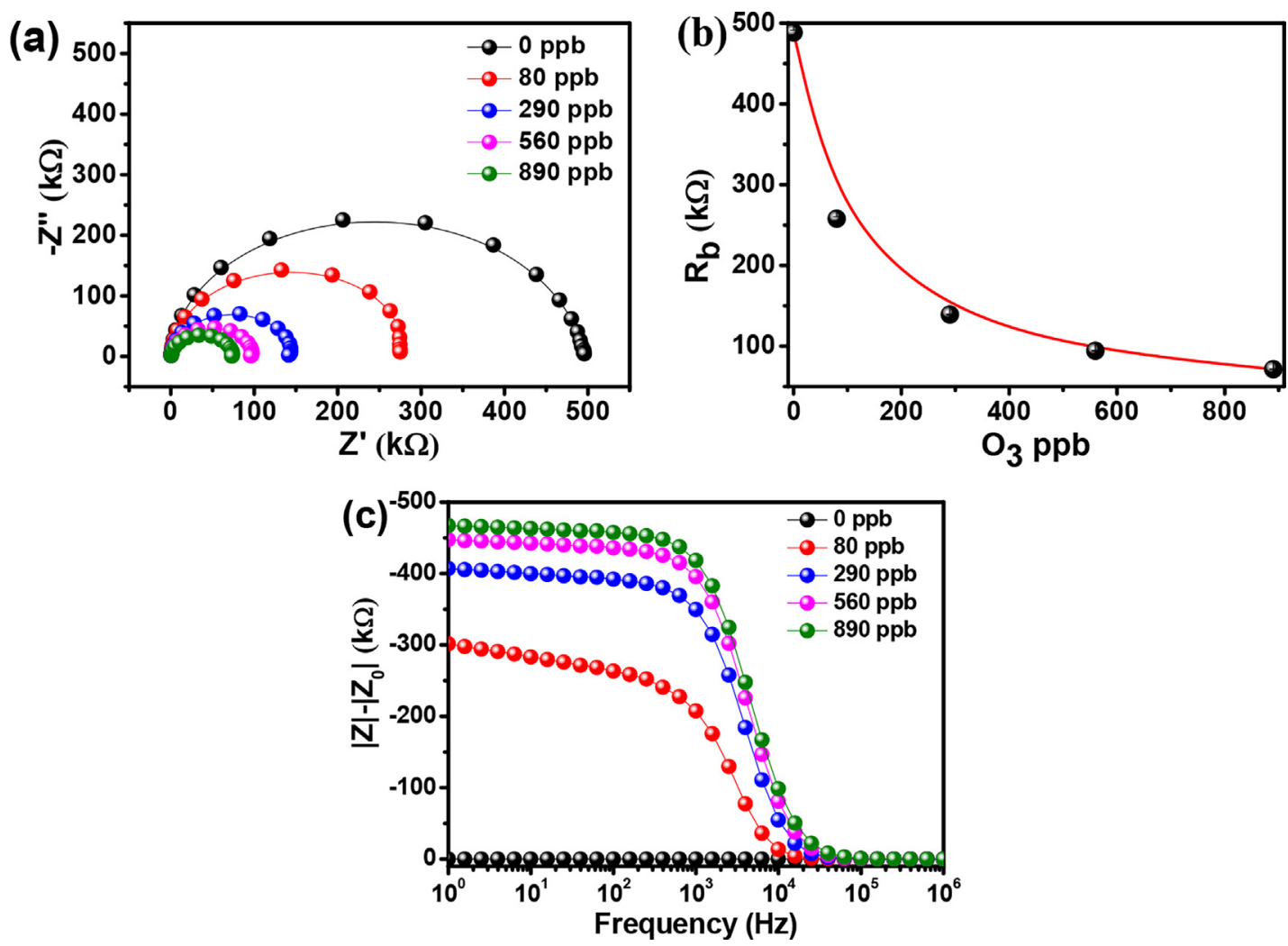

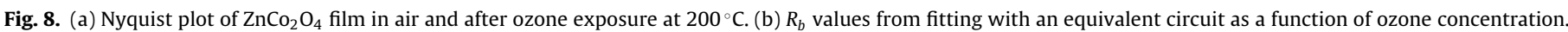
(c) Relative magnitude impedance spectra of $\mathrm{ZnCo}_{2} \mathrm{O}_{4}$ sample at $200{ }^{\circ} \mathrm{C}$ from $1 \mathrm{~Hz}$ to $1 \mathrm{MHz}$ for different ozone concentrations.

as found in parent compounds, is shown to be a surface dependent effect, with resistance being the appropriate parameter to monitor. Back to the impedance data in Fig. 8(a) and (c), we found no evidence of contribution from the material-electrode interface to the total impedance at the lowest frequencies. In fact, such a contribution would have involved higher capacitance values, normally approaching $\mu \mathrm{F}$ order of magnitude, instead of $\mathrm{nF}[67,68]$.

The finding above is consistent with an electronic transport mechanism with a non-blocking electrode effect. The adsorbed ozone molecules are expected to act as acceptors while electron trapping on the surface causes band bending, leading to an increase in free holes near the interface and therefore a decrease in the resistance. The yolk-shell microstructure could be thought of as a filter, where a molecule penetrates the shell and is "trapped" to interact with the inner surface of the shell and the outer surface of the core. Significantly, these yolk-shell microspheres possess high surface area to promote gas adsorption-desorption processes that enhance gas sensing performance.

The whole spectra of normalized magnitude impedance data for all the samples were analyzed with the multidimensional projection technique Interactive Document Map (IDMAP) using the PEx-Sensors software [70-72]. In IDMAP data dimensions are 


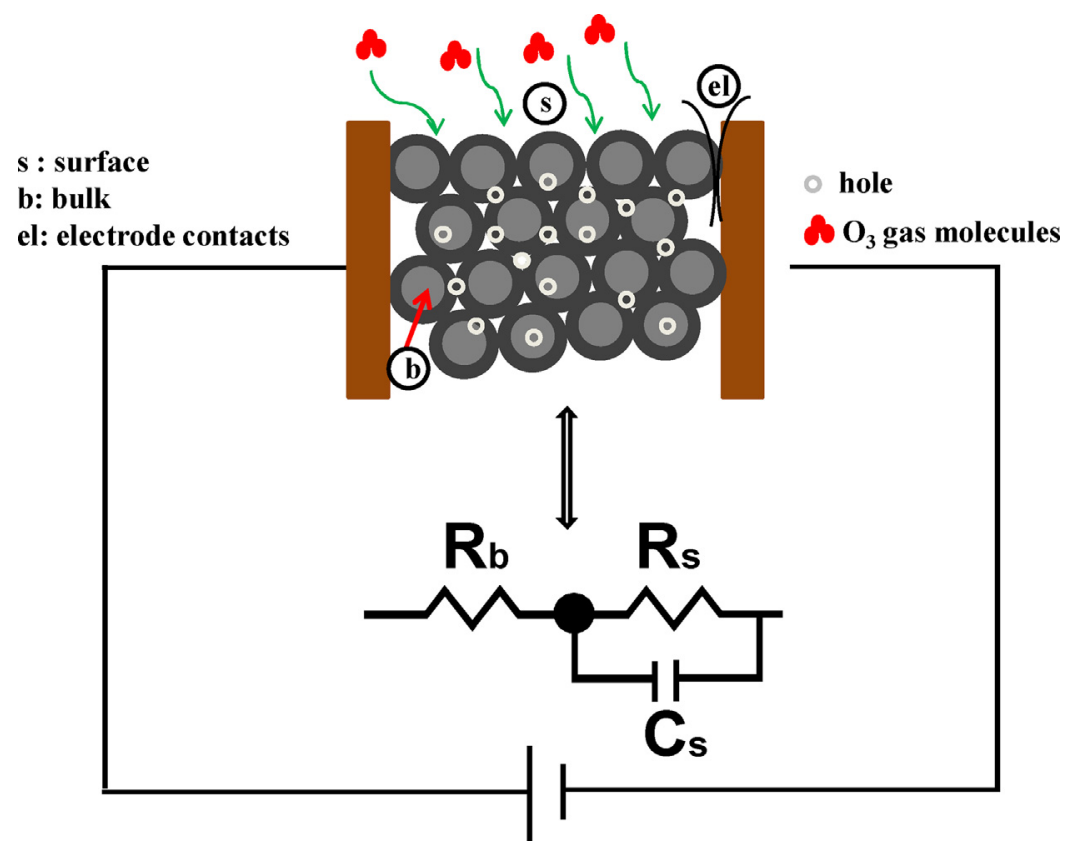

Fig. 9. Schematic representation of the gas sensing material and electrical equivalent circuit to fit the impedance data.

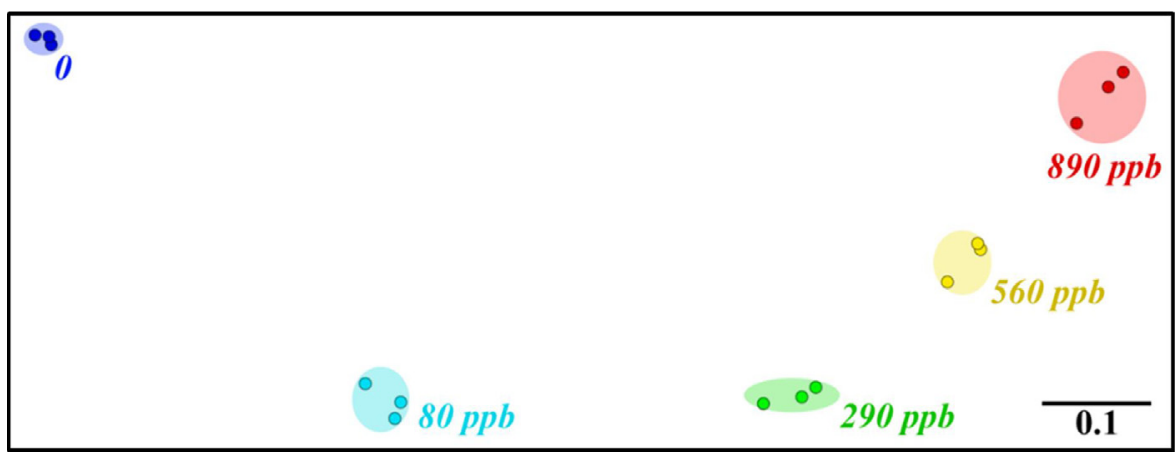

Fig. 10. IDMAP plot of normalized magnitude impedance spectra for different ozone gas concentrations. The scale bar represents the Euclidean distance of 0.1 .

Table 2

Parameters from fitting the impedance spectra using an RC equivalent circuit. $R_{b}$ is the bulk resistance (volume effect), while $R_{s}$ and $C_{s}$ are the yolk-shell-modified surface resistance and capacitance contributions to the total impedance.

\begin{tabular}{llll}
\hline $\mathrm{O}_{3}(\mathrm{ppb})$ & $\mathrm{R}_{\mathrm{b}}(\Omega)$ & $\mathrm{R}_{\mathrm{s}}(\mathrm{k} \Omega)$ & $\mathrm{C}_{\mathrm{s}}(\mathrm{pF})$ \\
\hline 0 & $458.4 \pm 37.1$ & $488.7 \pm 3.0$ & $90.7 \pm 0.7$ \\
80 & $427.5 \pm 62.2$ & $258.4 \pm 2.6$ & $90.7 \pm 1.2$ \\
290 & $442.9 \pm 30.2$ & $139.6 \pm 0.6$ & $91.0 \pm 0.6$ \\
560 & $447.2 \pm 26.5$ & $94.7 \pm 0.4$ & $91.5 \pm 0.6$ \\
890 & $455.7 \pm 24.6$ & $71.9 \pm 0.3$ & $92.0 \pm 0.6$ \\
\hline
\end{tabular}

reduced with the Fastmap technique, and then each spectrum was projected as a data point on the projected space. Dissimilarity was defined in terms of Euclidian distances between the spectra. The IDMAP plot in Fig. 10 confirms the efficiency of $\mathrm{ZnCo}_{2} \mathrm{O}_{4}$ for ozone sensing, since the distance between the points with no gas to the concentration $80 \mathrm{ppb}$ is large. Quantitatively, this distinguishing ability was represented by a silhouette coefficient of 0.91 [70], to be compared with the maximum value of 1.0.

\section{Conclusion}

We have shown that $\mathrm{ZnCo}_{2} \mathrm{O}_{4}$ microspheres can be synthesized by co-precipitation and subsequent annealing. The structure, morphology and composition of the $\mathrm{ZnCo}_{2} \mathrm{O}_{4}$ were confirmed with several methods, namely XRD, FE-SEM, TEM and XPS. The yolkshelled $\mathrm{ZnCo}_{2} \mathrm{O}_{4}$ sensor was highly sensitive to detect ozone gas down to $80 \mathrm{ppb}$ with both a.c. and d.c. electrical measurements, with fast response and recovery, and good selectivity. The mechanism of detection was found to be based on adsorption of ozone molecules on the $\mathrm{ZnCo}_{2} \mathrm{O}_{4}$ surface, as a layer of holes is created which affects the conductivity, as in a typical p-type semiconductor. Finally, the enhanced performance owing to the large surface area to volume ratio of $\mathrm{ZnCo}_{2} \mathrm{O}_{4}$ yolk-shelled microspheres is promising for developing further gas sensor devices to monitor the environment.

\section{Acknowledgements}

This work had financial support from CNPq and FAPESP (2012/15543-7, 2013/14262-7, 2013/07296-2, 2014/23546-1, 2016/23474-6). The authors are also grateful to Angelo L. Gobbi and Maria H.O. Piazzetta for the use of the Microfabrication Laboratory (LMF-20509) facilities to manufacture electrodes (LMF/LNNano-LNLS, Campinas, Brazil).

\section{Appendix A. Supplementary data}

Supplementary data associated with this article can be found, in the online version, at https://doi.org/10.1016/j.snb.2017.11.041. 


\section{References}

[1] J.-H. Lee, Gas sensors using hierarchical and hollow oxide nanostructures: overview, Sens. Actuators B: Chem. 140 (2009) 319-336.

[2] N. Barsan, D. Koziej, U. Weimar, Metal oxide-based gas sensor research: how to? Sens. Actuators B: Chem. 121 (2007) 18-35.

[3] A. Gusain, N.J. Joshi, P.V. Varde, D.K. Aswal, Flexible NO gas sensor based on conducting polymer poly[N-9'-heptadecanyl-2, 7-carbazole-alt-5, 5-(4', 7'-di-2-thienyl-2', 1', 3'-benzothiadiazole)] (PCDTBT), Sens. Actuators B: Chem. 239 (2017) 734-745.

[4] N. Joshi, V. Saxena, A. Singh, S.P. Koiry, A.K. Debnath, M.M. Chehimi, et al., Flexible H2S sensor based on gold modified polycarbazole films, Sens. Actuators B: Chem. 200 (2014) 227-234.

[5] G. Eranna, Metal Oxide Nanostructures as Gas Sensing Devices, CRC Press, 2016.

[6] B.R. Gurjar, L.T. Molina, C.S.P. Ojha, Air Pollution: Health and Environmental Impacts, CRC Press, 2010.

[7] N. Yamazoe, New approaches for improving semiconductor gas sensors, Sens. Actuators B: Chem. 5 (1991) 7-19.

[8] D.R. Miller, S.A. Akbar, P.A. Morris, Nanoscale metal oxide-based heterojunctions for gas sensing: a review, Sens. Actuators B: Chem. 204 (2014) 250-272.

[9] C. Wang, L. Yin, L. Zhang, D. Xiang, R. Gao, Metal oxide gas sensors: sensitivity and influencing factors, Sensors 10 (2010).

[10] P. Nafstad, J.J.K. Jaakkola, A. Skrondal, P. Magnus, Day care center characteristics and children's respiratory health, Indoor Air 15 (2005) 69-75

[11] G. Korotcenkov, B.K. Cho, Ozone measuring: what can limit application of SnO2-based conductometric gas sensors? Sens. Actuators B: Chem. 161 (2012) 28-44.

[12] L. Chaves Simoes, M. Simoes, Biofilms in drinking water: problems and solutions, RSC Adv. 3 (2013) 2520-2533

[13] C.Y. Wang, R.W. Becker, T. Passow, W. Pletschen, K. Köhler, V. Cimalla, et al., Photon stimulated sensor based on indium oxide nanoparticles I: wide-concentration-range ozone monitoring in air, Sens. Actuators B: Chem. 152 (2011) 235-240

[14] G. Korotcenkov, V. Brinzari, B.K. Cho, In2O3- and SnO2-based thin film ozone sensors: fundamentals, J. Sens. 2016 (2016) 31.

[15] A.C. Catto, L.F. da Silva, C. Ribeiro, S. Bernardini, K. Aguir, E. Longo, et al., An easy method of preparing ozone gas sensors based on $\mathrm{ZnO}$ nanorods, RSC Adv. 5 (2015) 19528-19533.

[16] C.-C. Jeng, P.J.H. Chong, C.-C. Chiu, G.-J. Jiang, H.-J. Lin, R.-J. Wu, et al., A dynamic equilibrium method for the $\mathrm{SnO}_{2}$-based ozone sensors using UV-LED continuous irradiation, Sens. Actuators B: Chem. 195 (2014) 702-706.

[17] K. Aguir, C. Lemire, D.B.B. Lollman, Electrical properties of reactively sputtered $\mathrm{WO}_{3}$ thin films as ozone gas sensor, Sens. Actuators B: Chem. 84 (2002) 1-5.

[18] L.F. da Silva, A.C. Catto, W. Avansi, L.S. Cavalcante, J. Andres, K. Aguir, et al., A novel ozone gas sensor based on one-dimensional (1D) [small alpha]- $\mathrm{Ag}_{2} \mathrm{WO}_{4}$ nanostructures, Nanoscale 6 (2014) 4058-4062.

[19] N. Joshi, L.F. da Silva, H. Jadhav, J.-C. M’Peko, B.B. Millan Torres, K. Aguir, et al., One-step approach for preparing ozone gas sensors based on hierarchical $\mathrm{NiCo}_{2} \mathrm{O}_{4}$ structures, RSC Adv. 6 (2016) 92655-92662.

[20] M. Epifani, E. Comini, J. Arbiol, E. Pellicer, P. Siciliano, G. Faglia, et al. Nanocrystals as very active interfaces: ultrasensitive room-temperature ozone sensors with $\mathrm{In}_{2} \mathrm{O}_{3}$ nanocrystals prepared by a low-temperature sol-gel process in a coordinating environment, J. Phys. Chem. C 111 (2007) 13967-13971.

[21] V.R. Mastelaro, S.C. Zílio, L.F. da Silva, P.I. Pelissari, M.I.B. Bernardi, J. Guerin, et al., Ozone gas sensor based on nanocrystalline $\mathrm{SrTi}_{1-\mathrm{x}} \mathrm{Fe}_{\mathrm{x}} \mathrm{O}_{3}$ thin films, Sens. Actuators B: Chem. 181 (2013) 919-924.

[22] H.J. Park, J. Kim, N.-J. Choi, H. Song, D.-S. Lee, Nonstoichiometric co-rich $\mathrm{ZnCO}_{2} \mathrm{O}_{4}$ hollow nanospheres for high performance formaldehyde detection at ppb levels, ACS Appl. Mater. Interfaces 8 (2016) 3233-3240.

[23] J. Liu, C. Liu, Y. Wan, W. Liu, Z. Ma, S. Ji, et al., Facile synthesis of $\mathrm{NiCO}_{2} \mathrm{O}_{4}$ nanorod arrays on $\mathrm{Cu}$ conductive substrates as superior anode materials for high-rate Li-ion batteries, CrystEngComm 15 (2013) 1578-1585.

[24] J. Xu, L. He, Y. Wang, C. Zhang, Y. Zhang, Preparation of bi-component $\mathrm{ZnO} / \mathrm{ZnCO}_{2} \mathrm{O}_{4}$ nanocomposites with improved electrochemical performance as anode materials for lithium-ion batteries, Electrochim. Acta 191 (2016) 417-425.

[25] Q. Ru, X. Song, Y. Mo, L. Guo, S. Hu, Carbon nanotubes modified for $\mathrm{ZnCO}_{2} \mathrm{O}_{4}$ with a novel porous polyhedral structure as anodes for lithium ion batteries with improved performances, J. Alloys Compd. 654 (2016) 586-592.

[26] S. Ratha, R.T. Khare, M.A. More, R. Thapa, D.J. Late, C.S. Rout, Field emission properties of spinel ZnCo2O4 microflowers, RSC Adv. 5 (2015) 5372-5378.

[27] K.B. Gawande, S.B. Gawande, S.R. Thakare, V.R. Mate, S.R. Kadam, B.B. Kale, et al., Effect of zinc: cobalt composition in $\mathrm{ZnCo}_{2} \mathrm{O}_{4}$ spinels for highly selective liquefied petroleum gas sensing at low and high temperatures, RSC Adv. 5 (2015) 40429-40436

[28] H. Behzad, F.E. Ghodsi, Effect of Zn content on the structural, optical, electrical and supercapacitive properties of sol-gel derived $\mathrm{ZnCo}_{2} \mathrm{O}_{4}$ nanostructured thin films, J. Mater. Sci.: Mater. Electron. 27 (2016) 6096-6107.

[29] X. Niu, W. Du, W. Du, Preparation and gas sensing properties of $\mathrm{ZnM}_{2} \mathrm{O}_{4}$ $(\mathrm{M}=\mathrm{Fe}, \mathrm{Co}, \mathrm{Cr})$, Sens. Actuators B: Chem. 99 (2004) 405-409.
[30] G.-Y. Zhang, B. Guo, J. Chen, $\mathrm{MCO}_{2} \mathrm{O}_{4}(\mathrm{M}=\mathrm{Ni}, \mathrm{Cu}, \mathrm{Zn})$ nanotubes: template synthesis and application in gas sensors, Sens. Actuators B: Chem. 114 (2006) 402-409.

[31] R. Zhao, Q. Li, C. Wang, L. Yin, Highly ordered mesoporous spinel $\mathrm{ZnCo}_{2} \mathrm{O}_{4}$ as a high-performance anode material for lithium-ion batteries, Electrochim. Acta 197 (2016) 58-67.

[32] X. Xu, K. Cao, Y. Wang, L. Jiao, 3D hierarchical porous $\mathrm{ZnO} / \mathrm{ZnCo}_{2} \mathrm{O}_{4}$ nanosheets as high-rate anode material for lithium-ion batteries, J. Mater. Chem. A 4 (2016) 6042-6047.

[33] F. Sun, X. Li, L. Liu, J. Wang, Novel Zn-M-O (M=Sn, Co) sensing electrodes for selective mixed potential $\mathrm{CO} / \mathrm{C}_{3} \mathrm{H}_{8}$ sensors, Sens. Actuators B: Chem. 184 (2013) 220-227

[34] T. Liu, J. Liu, Q. Liu, D. Song, H. Zhang, H. Zhang, et al., Synthesis, characterization and enhanced gas sensing performance of porous $\mathrm{ZnCo}_{2} \mathrm{O}_{4}$ nano/microspheres, Nanoscale 7 (2015) 19714-19721.

[35] L. Lu, S. Xu, Z. Luo, S. Wang, G. Li, C. Feng, Synthesis of $\mathrm{ZnCo}_{2} \mathrm{O}_{4}$ microspheres with $\mathrm{Zn}_{0.33} \mathrm{Co}_{0.67} \mathrm{CO}_{3}$ precursor and their electrochemical performance, J. Nanopart. Res. 18 (2016) 183.

[36] J.Y. Dong, N. Zhang, S.Y. Lin, T.T. Chen, M.Y. Zhang, L.L. Wu, et al., Effect of morphology of $\mathrm{ZnCO}_{2} \mathrm{O}_{4}$ nanostructures on electrochemical performance, Nano 11 (2016) 1650089.

[37] L. Hu, B. Qu, C. Li, Y. Chen, L. Mei, D. Lei, et al., Facile synthesis of uniform mesoporous $\mathrm{ZnCo}_{2} \mathrm{O}_{4}$ microspheres as a high-performance anode material for Li-ion batteries, J. Mater. Chem. A 1 (2013) 5596-5602.

[38] C.R. Mariappan, R. Kumar, G. Vijaya Prakash, Functional properties of $\mathrm{ZnCO}_{2} \mathrm{O}_{4}$ nano-particles obtained by thermal decomposition of a solution of binary metal nitrates, RSC Adv. 5 (2015) 26843-26849.

[39] D. Wang, X. Qi, H. Gao, J. Yu, Y. Zhao, G. Zhou, et al., Fabricating hierarchical porous $\mathrm{ZnCo}_{2} \mathrm{O}_{4}$ microspheres as high-performance anode material for lithium-ion batteries, Mater. Lett. 164 (2016) 93-96.

[40] S. Khalid, C. Cao, L. Wang, Y. Zhu, Microwave assisted synthesis of porous $\mathrm{NiCO}_{2} \mathrm{O}_{4}$ microspheres: application as high performance asymmetric and symmetric supercapacitors with large areal capacitance, Sci. Rep. 6 (2016) 22699.

[41] F. Iacomi, G. Calin, C. Scarlat, M. Irimia, C. Doroftei, M. Dobromir, et al., Functional properties of nickel cobalt oxide thin films, Thin Solid Films 520 (2011) 651-655

[42] H.S. Jadhav, R.S. Kalubarme, C.-N. Park, J. Kim, C.-J. Park, Facile and cost effective synthesis of mesoporous spinel $\mathrm{NiCO}_{2} \mathrm{O}_{4}$ as an anode for high lithium storage capacity, Nanoscale 6 (2014) 10071-10076.

[43] N.H. Perry, T.O. Mason, Phase equilibria of the zinc oxide-cobalt oxide system in air, J. Am. Ceram. Soc. 96 (2013) 966-971.

[44] H. Long, A. Harley-Trochimczyk, S. Cheng, H. Hu, W.S. Chi, C. Carraro, et al., Nanowire-assembled hierarchical $\mathrm{ZnCo}_{2} \mathrm{O}_{4}$ microstructure integrated with low power microheater for highly sensitive formaldehyde detection, ACS Appl. Mater. Interfaces 8 (2016) 31764-31771.

[45] J. Li, J. Wang, D. Wexler, D. Shi, J. Liang, H. Liu, et al., Simple synthesis of yolk-shelled $\mathrm{ZnCo}_{2} \mathrm{O}_{4}$ microspheres towards enhancing the electrochemical performance of lithium-ion batteries in conjunction with a sodium carboxymethyl cellulose binder, J. Mater. Chem. A 1 (2013) 15292-15299.

[46] P.H. Suman, A.A. Felix, H.L. Tuller, J.A. Varela, M.O. Orlandi, Comparative gas sensor response of $\mathrm{SnO}_{2}, \mathrm{SnO}$ and $\mathrm{Sn}_{3} \mathrm{O}_{4}$ nanobelts to $\mathrm{NO}_{2}$ and potential interferents, Sens. Actuators B: Chem. 208 (2015) 122-127.

[47] R. Haul, S. J. Gregg, K. S. W. Sing: adsorption, surface area and porosity. 2. Auflage, Academic Press London 1982. 303 Seiten, Preis: \$ 49.50, Berichte der Bunsengesellschaft für physikalische Chemie 86 (1982), 957-957.

[48] X. Zhou, G. Chen, J. Tang, Y. Ren, J. Yang, One-dimensional $\mathrm{NiCo}_{2} \mathrm{O}_{4}$ nanowire arrays grown on nickel foam for high-performance lithium-ion batteries, J. Power Sources 299 (2015) 97-103.

[49] T. Wagner, S. Haffer, C. Weinberger, D. Klaus, M. Tiemann, Mesoporous materials as gas sensors, Chem. Soc. Rev. 42 (2013) 4036-4053.

[50] T.-D. Nguyen, From formation mechanisms to synthetic methods toward shape-controlled oxide nanoparticles, Nanoscale 5 (2013) 9455-9482.

[51] S. Vijayanand, P.A. Joy, H.S. Potdar, D. Patil, P. Patil, Nanostructured spinel $\mathrm{ZnCo}_{2} \mathrm{O}_{4}$ for the detection of LPG, Sens. Actuators B: Chem. 152 (2011) $121-129$.

[52] J.F. Marco, J.R. Gancedo, M. Gracia, J.L. Gautier, E.I. Rios, H.M. Palmer, et al., Cation distribution and magnetic structure of the ferrimagnetic spinel $\mathrm{NiCO}_{2} \mathrm{O}_{4}$, J. Mater. Chem. 11 (2001) 3087-3093.

[53] A. La Rosa-Toro, R. Berenguer, C. Quijada, F. Montilla, E. Morallón, J.L. Vázquez, Preparation and characterization of copper-doped cobalt oxide electrodes, J. Phys. Chem. B 110 (2006) 24021-24029.

[54] H.S. Jadhav, S.M. Pawar, A.H. Jadhav, G.M. Thorat, J.G. Seo, Hierarchical mesoporous 3D flower-like $\mathrm{CuCo}_{2} \mathrm{O}_{4} / \mathrm{NF}$ for high-performance electrochemical energy storage, Sci. Rep. 6 (2016) 31120.

[55] A.C. Catto, L.F. da Silva, M.I.B. Bernardi, S. Bernardini, K. Aguir, E. Longo, et al., Local structure and surface properties of $\mathrm{Co}_{\mathrm{x}} \mathrm{Zn}_{1-\mathrm{x}} \mathrm{O}$ thin films for ozone gas sensing, ACS Appl. Mater. Interfaces 8 (2016) 26066-26072.

[56] D. Liu, Y. Lv, M. Zhang, Y. Liu, Y. Zhu, R. Zong, et al., Defect-related photoluminescence and photocatalytic properties of porous $\mathrm{ZnO}$ nanosheets, J. Mater. Chem. A 2 (2014) 15377-15388.

[57] A. Singh, A. Kumar, A. Kumar, S. Samanta, N. Joshi, V. Balouria, et al., Bending stress induced improved chemiresistive gas sensing characteristics of flexible cobalt-phthalocyanine thin films, Appl. Phys. Lett. 102 (2013) 132107. 
[58] A. Kumar, N. Joshi, S. Samanta, A. Singh, A.K. Debnath, A.K. Chauhan, et al., Room temperature detection of $\mathrm{H}_{2} \mathrm{~S}$ by flexible gold-cobalt phthalocyanine heterojunction thin films, Sens. Actuators B: Chem. 206 (2015) 653-662.

[59] L.F. Da Silva, O.F. Lopes, A.C. Catto, W. Avansi, M.I.B. Bernardi, M.S. Li, et al, Hierarchical growth of $\mathrm{ZnO}$ nanorods over $\mathrm{SnO}_{2}$ seed layer: insights into electronic properties from photocatalytic activity, RSC Adv. 6 (2016) 2112-2118.

[60] L.F. da Silva, V.R. Mastelaro, A.C. Catto, C.A. Escanhoela Jr., S. Bernardini, S.C. Zílio, et al., Ozone and nitrogen dioxide gas sensor based on a nanostructured $\mathrm{SrTi}_{0.85} \mathrm{Fe}_{0.15} \mathrm{O}_{3}$ thin film, J. Alloys Compd. 638 (2015) 374-379.

[61] R. Kumar, G. Al-Dossary, A. Umar, Zinc oxide nanostructures for $\mathrm{NO}_{2}$ gas-sensor applications: a review, Nano-Micro Lett. 7 (2015) 97-120

[62] G. Eranna, B.C. Joshi, D.P. Runthala, R.P. Gupta, Oxide materials for development of integrated gas sensors-a comprehensive review, Crit. Rev. Solid State Mater. Sci. 29 (2004) 111-188.

[63] Y. Qin, F. Zhang, Y. Chen, Y. Zhou, J. Li, A. Zhu, et al., Hierarchically porous CuO hollow spheres fabricated via a one-pot template-free method for high-performance gas sensors, J. Phys. Chem. C 116 (2012) 11994-12000.

[64] C. Cantalini, M. Post, D. Buso, M. Guglielmi, A. Martucci, Gas sensing properties of nanocrystalline $\mathrm{NiO}$ and $\mathrm{CO}_{3} \mathrm{O}_{4}$ in porous silica sol-gel films, Sens. Actuators B: Chem. 108 (2005) 184-192.

[65] C.-H. Wu, G.-J. Jiang, K.-W. Chang, C.-W. Lin, K.-L. Chen, Highly sensitive amorphous In-Ga-Zn-O films for ppb-level ozone sensing: effects of deposition temperature, Sens. Actuators B: Chem. 211 (2015) 354-358.

[66] G. Korotcenkov, Metal oxides for solid-state gas sensors: what determines our choice? Mater. Sci. Eng.: B 139 (2007) 1-23.

[67] J.R. Macdonald, W.R. Kenan, Impedance Spectroscopy: Emphasizing Solid Materials and Systems, Wiley, 1987

[68] A. Delgado, M.F. García-Sánchez, J.-C. M’Peko, A.R. Ruiz-Salvador, G. Rodríguez-Gattorno, Y. Echevarría, et al., An elementary picture of dielectric spectroscopy in solids: physical basis, J. Chem. Educ. 80 (2003) 1062.

[69] D.M. Taylor, A.G. Macdonald, AC admittance of the metal/insulator/electrolyte interface, J. Phys. D: Appl. Phys. 20 (1987) 1277.

[70] J.C. Soares, F.M. Shimizu, A.C. Soares, L. Caseli, J. Ferreira, O.N. Oliveira, Supramolecular control in nanostructured film architectures for detecting breast cancer, ACS Appl. Mater. Interfaces 7 (2015) 11833-11841.

[71] A.C. Soares, J.C. Soares, F.M. Shimizu, M.E. Melendez, A.L. Carvalho, O.N. Oliveira, Controlled film architectures to detect a biomarker for pancreatic cancer using impedance spectroscopy, ACS Appl. Mater. Interfaces 7 (2015) $25930-25937$

[72] J.C. Soares, A.C. Soares, P.A.R. Pereira, V.D.C. Rodrigues, F.M. Shimizu, M.E. Melendez, et al., Adsorption according to the Langmuir-Freundlich model is the detection mechanism of the antigen p53 for early diagnosis of cancer, Phys. Chem. Chem. Phys. 18 (2016) 8412-8418.

\section{Biographies}

Dr. Nirav Joshi received his Ph.D. degree in Applied Physics from M.S. University of Baroda, India in 2012. Currently, he is working as a postdoctoral fellow in the University of California, Berkeley, USA. Over the years, he worked on high dielectric constant materials, polymer nanocomposite for capacitor and supercapacitor applications. His present research interests are synthesis and characterization of metal semiconductor oxides, conducting polymers, gas sensors and Langmuir-Blodgett thin films.

Dr. Luís Fernando da Silva is currently professor at Department of Physics, Federal University of São Carlos, Brazil. He received his PhD in Materials and Engineering from São Carlos School of Engineering, University of São Paulo (Brazil) with a Postdoctoral fellowship in the Laboratory for Multifunctional Materials, Department of Materials, at ETH Zürich, Switzerland. His research interests mostly deals with synthesis of oxide compounds via chemical methods and the characterization of these compounds by X-ray absorption spectroscopy (XAS), photoluminescence, transmission and scanning electron microscopy and the electrical gas sensing properties of these oxide compounds.

Dr. Harsharaj S. Jadhav received his Ph.D degree from Chonnam national university, Gwangju, South Korea in 2015 and currently working as research professor at Myongji university, south korea. During Ph.D, he worked on protected lithium electrode and different cathode materials for Li-air battery. Currently his research interest is in synthesis of several nanomaterials and composites for energy storage and conversion applications such as secondary batteries (Li-ion, Li-S, Metal-air), supercapacitors and fuel cells.
Dr. Flavio M. Shimizu obtained his degree in Physics (2005), MSc (2008) and PhD (2012) in Materials Science and Technology (POSMat) from Universidade Estadual Paulista (UNESP - Presidente Prudente, Brazil). He is now post-doctoral researcher from São Carlos Institute of Physics, São Paulo University (IFSC/USP São Carlos, Brazil) working on the development of microelectrodes and nanostructured films for applications in sensing and biosensing and information visualization techniques.

Dr. Pedro H. Suman received his degree in Physics (2006), MSc degree (2012) and Ph.D. degree (2016) in Materials Science and Engineering from São Paulo State University (UNESP). Pedro also worked in collaboration with Prof. Tuller's group as a Ph.D. visiting student in the Department of Materials Science and Engineering at MIT. He is currently a postdoctoral researcher at UNESP and his research interest is mainly about the synthesis of $1 \mathrm{D}$ pure and hybrid semiconductor nanomaterials for chemical and UV sensors and field-effect transistors (FET) applications.

Dr.Jean-Claude M'Peko (PhD in physics, 1998, University of Havana, Cuba) is Professor MS3 of the Institute of Physics of São Carlos (IFSC), University of São Paulo (USP), Brazil, since 2004. His work involves studying correlation between (micro) structural characteristics and (di) electrical properties of materials (mainly dielectrics, ion conductors and ferroelectrics). This includes discriminating between bulk and interface (e.g., grain boundary) contributions to the total dielectric response of materials (polarization, electrical conduction and relaxation processes monitored through dielectric spectroscopy). In addition, as most of these materials are in the form of electroceramics (bulk but also films), investigating on the synthesis and sintering of materials, including electric field-assisted flash sintering, has also been and is part of his work.

Dr. Marcelo Ornaghi Orlandi is physicist with $\mathrm{PhD}$ in Material Science and Engineering field by Federal University of São Carlos (2005) having a professor position at São Paulo State University since 2006. In the last few years the main focus of Dr. Orlandi research has been the controllable growth and modeling of nanomaterials and the sensor response of nanomaterials. Other areas of interest are transport in nanomaterials and electron microscopy.

Prof. Jeong Gil Seo received his Ph.D. degree from Seoul National University, South Korea, in 2011. After one year as senior researcher in Samsung Advanced Institute of Technology (SAIT), he joined as an Assistant Professor in Department of Energy Science and Technology, Myongji University in South Korea, and then later became an Associate Professor. His research areas include (i) Design and synthesis of nanostructured inorganic materials for catalytic reactions (ii) electrochemical devices for energy conversion and storage.

Valmor Roberto Mastelaro is currently associated professor at the Institute of Physics of São Carlos, University of Sao Paulo, Brazil. He received his Doctor in science from Université Paris XI(France) in 1992. He research interests mostly deal with structural characterization of inorganic materials by X-ray diffraction spectroscopy (XAS) and electrical properties of perovskite oxide based ceramic materials. He is the (co) author of over 110 papers in international peer-reviewed journals.

Osvaldo N. Oliveira Jr. is a physics professor at the São Carlos Institute of Physics, University of São Paulo, Brazil. He has led research into the fabrication of novel materials in the form of ultrathin films obtained with the Langmuir-Blodgett and self-assembly techniques. Most of this work has been associated with fundamental properties of ultrathin films with molecular control, but technological aspects have also been addressed in specific projects. This is the case of an electronic tongue, whose response to a number of tastants is considerably more sensitive than the human gustatory system and the use of chitosan nanostructured films for covering textiles. In recent years, Prof. Oliveira has pioneered the combined use of methods from distinct fields of science, with the merge of methods of statistical physics and computer science to process text, and use of information visualization to enhance the performance of sensing and biosensing. This pioneering work is associated with the merge of nanotechnology with Big Data Analytics, bound to yield developments in technology such as computer-aided diagnosis systems. 